Nig. J. Biotech. Vol. 37(1): 101-108 (June 2020)

ISSN: 01891731

Available online at

http://www.ajol.info/index.php/njb/index

and www.biotechsocietynigeria.org

DOI: https://dx.doi.org/10.4314/njb.v37i1.11

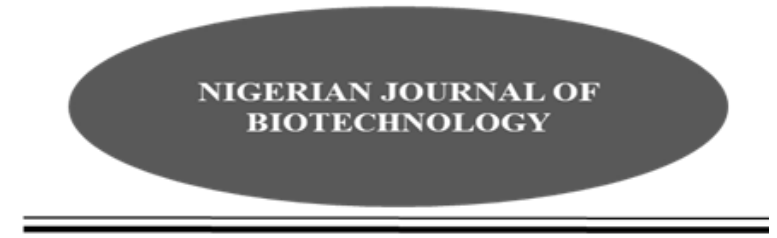

\title{
Applications of molecular markers in Genetic Diversity Studies of maize
}

\author{
1,2 Degife Asefa Zebire \\ ${ }^{1}$ Pan African University of Life and Earth Sciences Institute (including Health and Agriculture) (PAULESI), \\ University of Ibadan, Nigeria. \\ ${ }^{2}$ Arba Minch University, College of Agricultural Sciences, Department of Plant Science, P.O.box 21, Arba \\ Minch, Ethiopia
}

\begin{abstract}
Molecular markers are efficient for exploiting variations in genotypes as they are not influenced by environmental factors and also speed up breeding programs. They are used to detect large numbers of distinct divergence between genotypes at the DNA level. Genetic diversity study helps to estimate the relationship between inbred lines to make the best hybrid combinations. Lines which are clustered in different heterotic groups are considered as the best hybrid combinations to carry out further breeding activities. Molecular markers are used to meet a number of objectives, including genetic diversity analysis and prediction of hybrid performances in divergent crop species. Agro-morphological and molecular markers have been utilized to study genetic diversity so far. In maize, the uses of molecular markers are important for the evaluation of genetic diversity of inbred lines and in clustering them into heterotic groups. These markers determine genetic similarity of the lines and are used to assess the genetic diversity of maize. Molecular markers have proven valuable for genetic diversity analysis of many crop species and genetically diverse lines are important to improve hybrid breeding.
\end{abstract}

Keyword: Molecular marker; Genetic diversity; Genetic variation, Diversity Array technology; cluster analysis

Corresponding email: asefadegife@gmail.com or degife.asefa@amu.edu.et

\section{Introduction}

Maize (Zea mays $L$ ) is a well-known cereal crop in its adaptability and importance worldwide. A maize breeding program requires genetically diverse source material. Genetically diverse and complementary elite inbred lines can play a significant role in the development of maize hybrids with maximum expression of heterosis (Adeyemo et al., 2011; Singh et al ., 2018). Similarly, Menkir et al. (2010) reported that better hybrids can be obtained in crosses of parents from a diverse origin than hybrids formed from lines with the same genetic background. Consequently, accurate characterization of inbred lines using molecular and morphological markers is important for effective breeding ( $\mathrm{Xu}$ et al, 2013).

Maize is predominantly a cross-pollinated crop showing the highest phenotypic and genotypic variability from generation to generation (Molin et 
al., 2013; Nyaligwa et al., 2015). The presence of genetic variability allows for further improvement of the crop. The levels of recombination in maize are high (Huihua Fu, 2002) and disparately it shows low levels of linkage disequilibrium (Remington et al., 2001). Maize is an outcrossing species, and it has large population sizes (Vigouroux et al., 2002). Therefore, it is important to reduce complexity by making strong selection that could have retained near normal levels of diversity (Wang et al., 1999). This, in turn, minimizes the possibility of detecting false positives, i.e., low diversity can be reported due to unselected genes. However, in maize, a relatively modest effect of domestication bottleneck can be observed as a result of unselected genes retaining high diversity and can be readily eminent from those undermined by selection (Eyre-Walker et la., 1998).

The presence of genetic variability allows for further improvement of the crop. Various agroecological conditions provide a possibility of making selection on the genes involved that could be identified by using different tests such as genomic scans for the selected gene. Single nucleotide polymorphism (SNP) marker technology provides a great advantage of high throughput, scanning the genome for a good selection. The SNP discovered in teosinte can then be assayed in diverse maize lines, or again, examined through the SNP mapper's trash bin of monomorphic loci (Vigouroux et al., 2002).

Existence of strong selection placed up on a gene could create a suitable condition to find the reasonable expectation that neighbouring genes will have retained near normal levels of diversity during domestication of maize (Wang et al., 1999). This situation reduces the possibility of detecting false positives due to hitchhiking effect. The relatively modest effect of domestication bottleneck can be observed in maize, so unselected genes retain high diversity and can be readily distinguished from those affected by selection (Eyre-Walker et la., 1998).

Knowledge on the genetic diversity and relationships among maize inbred lines is indispensable to identify promising combinations for the exploitation of heterosis and establishment of heterotic groups for use as source materials in a breeding program. Molecular markers have proven valuable for genetic diversity analysis of many crop species (Yoseph et al. , 2014; Mengesha et al., 2017). Extremely high levels of natural genetic variation existed in maize at both morphological and molecular levels (Yan et al., 2010). The amount of genetic variability found in a population under improvement governs the type of breeding schemes to be used for population improvement and the expected level of progress that we want to make (Shahi and Singh, 1985). Therefore, genetic diversity affects the potential genetic gain through selection. Availability of sufficient genetic variability enhances selection efficiency. Classification of germplasm into heterotic groups in hybrid breeding needs genetic diversity information. Prediction of hybrid performance can be made using genetic distance based on molecular markers (Makumbi et al., 2011).

Genetic diversity is important to identify groups with similar genotypes for conserving, evaluating and utilising genetic resources. It is also useful for studying the diversity of different germplasms as possible sources of genes that can improve the performance of cultivars. Moreover, it helps to determine the uniqueness and distinctness of phenotypic characteristics and genetic constitutions of closely related organisms with the purpose of protecting the breeder's intellectual property rights as reviewed by (Geleta et al., 2006).

Assessment of genetic diversity using DNA-based techniques, such as the use of molecular markers, at the DNA sequence level has been proven very effective . Among these markers, amplified fragment length polymorphism (AFLP), randomly amplified polymorphic DNA (RAPD), restriction fragment length polymorphism (RFLP), simple sequence repeats (SSR) and single nucleotide polymorphism (SNP) have been used to assess information on the genetic divergence of parental inbred lines (Menkir et al., 2004; Geleta et al., 2006; Badu-Apraku et al., 2013). Liu et al. (2003) proved a clear difference of the non-stiff stalk, stiff stalk and tropical/subtropical lines and concluded that the stiff stalk lines are the most divergent and can provide a strong heterotic response in crosses with other maize inbred lines. 
Of these molecular markers, RFLP is the most commonly used one in the assessment of genetic diversity in plant species, but due to the labour intensive and time-consuming nature of RFLPs, recently developed PCR-based marker techniques, like SSRs and AFLPs, are playing an increasingly important role in such studies

This review mainly presents and discusses the most relevant advances in the development and application of molecular markers in genetic diversity study in maize breeding. It introduces the most relevant DNA based molecular markers and provides examples of their application in maize genetic diversity study. The objective is to provide modern breeders with a recent synthetic view of how molecular markers can effectively improve the efficiency of breeding programs.

Application of different molecular markers for genetic diversity assessment in maize

\section{Use of RFLP for studying genetic diversity}

Estimation of hybrid performance in maize has a vital role and is becoming an issue for many years (Hallauer and Miranda Filho, 1988). The construction of genetic linkage maps based on molecular markers for maize can provide effective means for predicting hybrid performance and heterotic (Ajmone et al., 1998). Restrictionfragment length polymorphisms (RFLPs) become a solution to many of the constraints associated with the study of the inheritance of morphological traits in maize (Ajmone et al., 1998). It exhibits abundant polymorphisms and provides a precise measurement of the genetic similarity of genotypes (Messmer et al., 1991). Similarly, RFLP markers allow related lines and inbred lines from common genetic background to be identified, but to estimate genetic distances with precision, a large number of probe-enzyme combinations is needed (Messmer et al., 1991). According to Garcia et al. (2004), AFLP markers are considered as the best choice of markers and efficient for studying diversity and assessing genetic relationships between tropical maize inbred lines. AFLPs can also provide good levels of precision in its genetic estimates and predict single-cross performance. Several studies have confirmed that RFLP-based estimates of genetic relationship can be used to assign maize inbred lines to heterotic groups (Benchimol et al., 2000; Warburton et al., 2005). Determination of genetic distance was later used to predict hybrid performance. RFLP has been employed to investigate genetic distances among tropical maize materials and their relationship to heterotic group allocation and hybrid performance. The study revealed that there is a high correlation for line crosses from the same heterotic group and low correlation for line combinations from different heterotic groups of parental GDs with single crosses and their heterosis for grain yield. This suggests that RFLPbased GDs are efficient and reliable to assess and allocate genotypes from tropical maize populations into heterotic groups. Though, RFLPbased GDs are not suitable for estimating the performance of line crosses from genetically diverse heterotic groups (Benchimol et al., 2000). In maize, RFLP markers are widely used to carry out the similarity of genotype at the DNA level (Melchinger, 1999). These markers take advantage in maize by exploiting a large number of polymorphic loci found in breeding materials (Messmer et al., 1991). Elite inbred lines adapted to the U.S. Corn Belt and early-maturing European maize inbred lines revealed that RFLPs are important to a) define heterotic groups b) assign inbred lines to heterotic groups, c) show genetic relationships among lines and d) differentiate diverse germplasm sources. However, RFLP markers are constrained by labour and time utilization i.e. they utilize more labour and time. Therefore, looking at other alternative marker techniques like PCR- based ones including AFLP (Amplified Fragment Length Polymorphism) and SSR (Simple Sequence Polymorphism) is essential (Jones et al., 1998).

\section{Using AFLP (Amplified Fragment Length Polymorphism) for studying genetic diversity}

AFLP markers are genomic restriction fragments detected after selective amplification using the polymerase chain reaction (PCR). AFLPs are considered as Mendelian markers with a number of interesting features relative to RFLPs. Thus, they are a powerful tool for DNA fingerprinting of genomes of any origin or complexity, including those of maize (Geleta et al., 2006). The AFLPs are very useful in analysis variation within-species 
because they allow the rapid acquisition of a large amount of genetic information due to their capability to simultaneously identify a large number of amplification products reviewed in (Hartings et al., 2008). The AFLP technique is largely applicable in maize to construct genetic maps or to study phylogenetic relationships, genetic diversity and other applications (Ajmone et al., 1998).

AFLP markers also have good association with the result obtained from the RFLP system and is a fast and reliable system capable of supporting a multiplex approach that does not require previous knowledge of DNA sequencing (Garcia et al., 2004). There is little information available on comparison of estimates of genetic relationship based on RFLP and AFLP marker types, but these two markers are known to be efficient for determining the genetic relationship of maize germplasm pools.

Use of Simple sequence repeat (SSR) markers for Diversity Study

SSR markers are co dominant in nature. SSR markers are very effective in discrimination and analysis of genetic relationships in quality protein maize genotypes (Bantte and Prasanna, 2003). The average number of alleles identified per microsatellite locus during screening is determined by the genetic diversity of the studied materials. However, other factors like the number of SSR loci and repeat types that affect the detection of polymorphic markers can contribute to allelic variation in the studied materials as reviewed by Legesse et al. (2007). For instance, Legesse et al. (2007) reported 3.85 average numbers of alleles using 27 SSR loci to screen some inbred lines, and this was considerably lower than previously reported results in maize. Warburton et al. (2002) reported 4.9 alleles with 85 SSR loci. The difference could be associated with the type of electrophoresis system used to screen the microsatellite loci in maize.

The informativeness of SSR loci and their potential to detect differences among the inbred lines based on their genetic relationships depend largely on polymorphic information content (PIC). SSR markers chiefly classify the inbred lines into different clusters, which generally agreed with their pedigree records and adaptation regimes. SSR markers are robust for diversity analysis and heterotic groupings in most maize inbred lines (Warburton et al., 2002).

In diversity study, clustering is common to identify the inbred lines into different groups. Legesse et al. (2007) reported clustering of inbred lines into five groups, which may be generalized into three main clusters representing the highland, the mid-altitude and the mixed group lines based on agro-ecology. The pedigree records of the materials also have a great contribution in grouping. Smith et al. (1997); Senior et al. (1998) and Reif et al. (2003) also demonstrated that the genetic distance estimated by SSR marker can be associated with the pedigree information in maize. On the other hand, groupings of the inbred lines based on their adaptation regimes (cluster I and IV) can also be evident based on the cluster analysis.

Use of Single nucleotide polymorphism (SNP) markers for Diversity Study

Single nucleotide polymorphism (SNP) markers are developed recently and effectively used in detecting genetic diversity. These markers gained significant attention because they are bi-allelic in nature and can be expressed at a much higher frequency in the genome than SSRs and other markers. Likewise, their genotyping can easily be automated (Jones et al., 2007). The genetic dissection of traits of economic importance and the application of marker-assisted genetic analysis and genomic selection in crops would be facilitated due to the availability of SNP genotyping platforms (Rafalski, 2002). Moreover, SNPs are a known class of sequence variability in the genome and thus have the potential to provide the highest map resolution (Jones et al., 2007; Jones et al., 2007). The recent development in high-throughput genotyping by sequencing (GBS) approaches, like DArTseq, becomes most efficient to characterize genetic diversity by complexity reduction methods (Wenzl et al., 2004; Elshire et al., 2011). Diversity Arrays Technology (DArT) can measure DNA variation at many genomic loci at a time without sequence information on a particular crop. This technology can be effectively applied to many crop species 
(including those with large genome sizes) for studying genetic diversity (Wenzl et al., 2004). DArT mainly detects the presence or absence of individual fragments in genomic representations as described by Jaccoud et al. (2001). The recently developed high- through put microarray-based DNA marker technology for detecting DNA polymorphism (diversity arrays technology, DArT) (Wenzl et al., 2004) becomes successful for the analysis of genetic diversity in many crop species like rice (Elshire et al., 2011), cassava (Xia et al., 2005) and pigeon pea (Yang et al., 2006).

\section{Conclusion}

Genetic diversity is important to identify groups of inbred lines for further utilization of hybrid development. It is also useful for studying the diversity of different germplasms as possible sources of genes that can improve the performance of cultivars. Genetic diversity markers help to determine the uniqueness and distinctness of phenotypic and genetic characters. DNA-based molecular marker technologies are useful tools for genetic similarity studies. Among these molecular markers, RFLP is most commonly used in the assessment of genetic diversity in plant species, but due to labour intensive and time-consuming nature of RFLPS, recently developed PCR-based marker techniques like SSRs and AFLPs are playing an increasingly important role in such studies. For instance, AFLP markers have the capacity to give several bands in a particular amplification. Depending on the purpose of the study and the availability of resources, SSR and SNP are still recognized as markers of choice to study genetic diversity.

\section{Conflict of interest}

The author declared that there is no conflict of interests and all sources used in this paper are properly cited and acknowledged.

\section{References}

Adeyemo, O., Menkir, A., Melaku, G., and Omidiji, O. (2011). Genetic diversity assessment and relationship among tropicalyellow endosperm maize inbred lines using SSR markers. Maydica, 56(1), 1-7.

Ajmone-Marsan, P., Castiglioni, P., Fusari, F., Kuiper, M., and Motto, M. (1998). Genetic diversity and its relationship to hybrid performance in maize as revealed by RFLP and AFLP markers. TAG Theoretical and Applied Genetics, 96(2), 219-227. https://doi.org/10.1007/s001220050730

Badu-Apraku, B., Oyekunle, M., Akinwale, R. O., and Aderounmu, M. (2013). Combining ability ahnd genetic diversity of extra-early white maize inbreds under stress and nonstress environments. Crop Science, 53(1), 9-26. https://doi.org/10.2135/cropsci2012.06.0381

Bantte, K., and Prasanna, B. M. (2003). Simple sequence repeat polymorphism in Quality Protein Maize (QPM) lines. Euphytica, 129(3), 337-344. https://doi.org/10.1023/A:1022257021205

Benchimol, L. L., de Souza jr, C. L., Garcia, A. A. F., Kono, P. M. S., Mangolin, C. A., Barbosa, A. M. M., and de Souza, A. P. (2000). Genetic diversity in tropical maize inbred lines: heterotic group assignment and hybrid performance determined by RFLP markers. Plant Breeding, 119(6), 491496. https://doi.org/10.1046/j.1439-

0523.2000.00539.x

Botha, A. M., Twumasi-Afriyie, S., Pixley, K. V., Myburg, A. A., and Legesse, B. W. (2007). Relationship between hybrid performance and AFLP based genetic distance in highland maize inbred lines. Euphytica, 162(3), 313-323. https://doi.org/10.1007/s10681-007-9503-6

Elshire, R. J., Glaubitz, J. C., Sun, Q., Poland, J. A., Kawamoto, K., Buckler, E. S., and Mitchell, S. E. (2011). A Robust, Simple Genotyping-bySequencing (GBS) Approach for High Diversity Species. PLOS ONE, 6(5), e19379. https://doi.org/10.1371/journal.pone.0019379

Eyre-Walker, A., Gaut, R. L., Hilton, H., Feldman, D. L., and Gaut, B. S. (1998). Investigation of the bottleneck leading to the domestication of maize. Proceedings of the National Academy of Sciences, 95(8). 
Garcia, A. A. F., Benchimol, L. L., Barbosa, A. M. M., Geraldi, I. O., Souza Jr., C. L., and Souza, A. P. de. (2004). Comparison of RAPD, RFLP, AFLP and SSR markers for diversity studies in tropical maize inbred lines. Genetics and Molecular Biology, 274), 579-588. https://doi.org/10.1590/S141547572004000400019

Geleta, N., Labuschagne, M. T., and Viljoen, C. D. (2006). Genetic diversity analysis in sorghum germplasm as estimated by AFLP, SSR and morpho-agronomical markers. Biodiversity and Conservation, 15(10), 3251-3265. https://doi.org/10.1007/s10531-005-0313-7

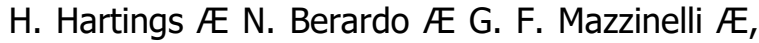
and P. Valoti $Æ A$. Verderio $Æ$ M. Motto. (2008). Assessment of genetic diversity and relationships among maize (Zea mays L.) Italian landraces by morphological traits and AFLP profiling. SpringerVerlag: Theory Application of Genetics, 117, 831842. https://doi.org/10.1007/s00122-008-0823-2

Hallauer, A. R., and Miranda Filho, J. B. (1988). Quantitative genetics in maize breeding. Iowa State University Press. Retrieved from https://books.google.com.ng/books/about/Quan titative_Genetics_in_Maize_Breeding.html?id=CC FJAQAAIAAJandredir_esc $=y$

Huihua Fu, Z. Z. and H. K. D. (2002). Recombination rates between adjacent genic and retrotransposon regions in maize vary by 2 orders of magnitude. Proceedings of the National Academy of Sciences, 96(13), 7409-7414. https://doi.org/10.1073/pnas.96.13.7409

Jaccoud, D., Peng, K., Feinstein, D., and Kilian, A. (2001). Diversity Arrays: a solid state technology for sequence information independent genotyping. Nucleic Acids Research, 29(4), 25e25. https://doi.org/10.1093/nar/29.4.e25

Jones, C. J., Edwards, K. J., Castiglione, S., Winfield, M. O., Sala, F., Van der Wiel, C., and Karp, A. (1998). Reproducibility Testing of RAPDs by a Network of European Laboratories. In Molecular Tools for Screening Biodiversity ( $\mathrm{pp}$. 176-179). Dordrecht: Springer Netherlands. https://doi.org/10.1007/978-94-009-0019-6_35

Jones, E. S., Sullivan, H., Bhattramakki, D., and Smith, J. S. C. (2007). A comparison of simple sequence repeat and single nucleotide polymorphism marker technologies for the genotypic analysis of maize (Zea mays L.). Theoretical and Applied Genetics, 115(3), 361371. https://doi.org/10.1007/s00122-007-0570-9

Legesse W, B., Myburg, A., Pixley, K., and Botha M., A. (2007). Genetic diversity of African maize inbred lines revealed by SSR markers. Hereditas, 144(1), 10-17. https://doi.org/10.1111/j.2006.00180661.01921.x

Liu, K., Goodman, M., Muse, S., Smith, J., and E. B. (2003). Genetic structure and diversity among maize inbred lines as inferred from DNA microsatellites. Genetics Soc America. Retrieved from

http://www.genetics.org/content/165/4/2117.sh ort

Makumbi, D., Betrán, J. F., Bänziger, M., and Ribaut, J.-M. (2011). Combining ability, heterosis and genetic diversity in tropical maize (Zea mays L.) under stress and non-stress conditions. Euphytica, 180(2), 143-162. https://doi.org/10.1007/s10681-010-0334-5

Melchinger, A. E. (1999). Genetic Diversity and Heterosis. In The Genetics and Exploitation of Heterosis in Crops (Vol. acsesspubl, pp. 99-118). American Society of Agronomy, Crop Science Society of America. https://doi.org/10.2134/1999.geneticsandexploit ation.c10

Mengesha, W. A., Menkir, A., Unakchukwu, N., Meseka, S., Farinola, A., Girma, G., and Gedil, M. (2017). Genetic diversity of tropical maize inbred lines combining resistance to Striga hermonthica with drought tolerance using SNP markers. Plant Breeding, 136(3), 338-343. https://doi.org/10.1111/pbr.12479

Menkir, A., Melake-Berhan, A., The, C., Ingelbrecht, I., and Adepoju, A. (2004). Grouping of tropical mid-altitude maize inbred lines on the 
basis of yield data and molecular markers. TAG Theoretical and Applied Genetics, 108(8), 15821590. https://doi.org/10.1007/s00122-004-15850

Menkir, A., Adetimirin, V. O., Yallou, C. G., and Gedil, M. (2010). Relationship of Genetic Diversity of Inbred Lines with Diff erent Reactions to Striga hermonthica (Del.) Benth and the Performance of Their Crosses, 50, 602-611. https://doi.org/10.2135/cropsci2009.05.0247

Messmer, M. M., Melchinger, A. E., Lee, M., Woodman, W. L., Lee, E. A., and Lamkey, K. R. (1991). Genetic diversity among progenitors and elite lines from the Iowa Stiff Stalk Synthetic (BSSS) maize population: comparison of allozyme and RFLP data. Theoretical and Applied Genetics, 83(1), $\quad$ 97-107. https://doi.org/10.1007/BF00229231

Molin, D., Coelho, C. J., Máximo, D. S., Ferreira, F. S., Gardingo, J. R., and Matiello, R. R. (2013). Genetic diversity in the germplasm of tropical maize landraces determined using molecular markers. Genetics and Molecular Research, 12(1), 99-114.

https://doi.org/10.4238/2013.January.22.8

Nyaligwa, L., Hussein, S., Amelework, B., and Ghebrehiwot, H. (2015). Genetic diversity analysis of elite maize inbred lines of diverse sources using SSR markers. Maydica, 60(3).

Rafalski J.A. (2002). Novel genetic mapping tools in plants: SNPs and LD-based approaches. Elsevier, 162, 329-333. Retrieved from https://www.sciencedirect.com/science/article/pi i/S0168945201005878

Reif, J. C., Melchinger, A. E., Xia, X. C., Warburton, M. L., Hoisington, D. A., Vasal, S. K., and Frisch, M. (2003). Genetic Distance Based on Simple Sequence Repeats and Heterosis in Tropical Maize Populations. Crop Science, 43(4), 1275. https://doi.org/10.2135/cropsci2003.1275

Remington, D., Thornsberry, J., Yoshihiromatsuoka, Wilson, L., Whitt, S., Johndoebley, S., and Buckleriv. (2001).
Structureoflinkagedisequilibriumandphenotypic associationsinthemaizegenome. https://doi.org/10.1073/pnas.201394398

Senior, M. L., Murphy, J. P., Goodman, M. M., and Stuber, C. W. (1998). Utility of SSRs for Determining Genetic Similarities an Relationships in Maize Using an Agarose Gel System. Crop Science, 38(4), 1088. https://doi.org/10.2135/cropsci1998.0011183X0 03800040034x

Shahi, J.P and Singh, I. (1985). Estimation of genetic variability for grain yield and its components in a random mating population of maize. Crop Improvement (India). Retrieved from http://agris.fao.org/agris-

search/search.do?recordID =IN8600534

Singh, P., Sharma, V. K., and Kumar, P. (2018). Microsatellite marker dependent genetic divergence assessment within and among heterotic groups of tropical maize inbred lines. Maydica, (January 2019).

Smith, J. S. C., Chin, E. C. L., Shu, H., Smith, O. S., Wall, S. J., Senior, M. L., ... Ziegle, J. (1997). An evaluation of the utility of SSR loci as molecular markers in maize ( Zea mays L. ): comparisons with data from RFLPS and pedigree. TAG Theoretical and Applied Genetics, 95(1-2), 163-173.

https://doi.org/10.1007/s001220050544

Vigouroux, Y., Mcmullen, M., Hittinger, C. T., Houchins, K., Schulz, L., Kresovich, S., ... Doebley, J. (2002). Identifying genes of agronomic importance in maize by screening microsatellites for evidence of selection during domestication, 99(15), 9650-9655. https://doi.org/10.1073pnas.112324299

Wang, R.-L., Stec, A., Hey, J., Lukens, L., and Doebley, J. (1999). The limits of selection during maize domestication. Nature, 398(6724), 236239. https://doi.org/10.1038/18435

Warburton, M. L., Xianchun, X., Crossa, J., Franco, J., Melchinger, A. E., Frisch, M., and Hoisington, D. (2002). Genetic Characterization of CIMMYT Inbred Maize Lines and Open 
Pollinated Populations Using Large Scale Fingerprinting https://doi.org/10.2135/cropsci2002.1832

Warburton, M. L., Ribaut, J. M., Franco, J., Crossa, J., Dubreuil, P., and Betrán, F. J. (2005). Genetic characterization of 218 elite CIMMYT maize inbred lines using RFLP markers. Euphytica, 142(1-2), 97-106. https://doi.org/10.1007/s10681-005-0817-y

Wenzl, P., Carling, J., Kudrna, D., Jaccoud, D., Huttner, E., Kleinhofs, A., ... Phillips, R. L. (2004). Diversity Arrays Technology (DArT) for wholegenome profiling of barley. Retrieved from www.doublehelix.too.it

Xia, L., Peng, K., Yang, S., Wenzl, P., Carmen de Vicente, M., Fregene, M., and Kilian, A. (2005). DArT for high-throughput genotyping of Cassava (Manihot esculenta) and its wild relatives. Theoretical and Applied Genetics, 1106), 10921098. https://doi.org/10.1007/s00122-005-19374

Xu J, Liu L, Xu Y, Chen C, Rong T, Ali F, Zhou S, Wu F, Liu Y, Wang J, and Cao M, L. Y. (2013). Development and characterization of simple sequence repeat markers providing genome-wide coverage and high resolution in maize. - PubMed - NCBI. PMC, 20(5), 497-509. Retrieved from https://www.ncbi.nlm.nih.gov/pubmed/2380455 7

Yan, J., Yang, X., Shah, T., Sánchez-Villeda, H., Li, J., Warburton, M., and Xu, Y. (2010). Highthroughput SNP genotyping with the GoldenGate assay in maize. Molecular Breeding, 25(3), 441451. https://doi.org/10.1007/s11032-009-9343-2

Yang, S., Pang, W., Ash, G., Harper, J., Carling, J., Wenzl, P., ... Kilian, A. (2006). Low level of genetic diversity in cultivated Pigeonpea compared to its wild relatives is revealed by diversity arrays technology. Theoretical and Applied Genetics, 113(4), 585-595. https://doi.org/10.1007/s00122-006-0317-z

Yoseph, B., Anna-Maria, B., Alex, A., and er, A. M. (2014). A comparative study of molecular and morphological methods of describing genetic relationships in traditional Ethiopian highland maize. African Journal of Biotechnology, 4(7), 596-600. https://doi.org/10.5897/ajb2005.0003107 